\title{
Prostorje kot kulturni proizvod - Refleksija na današnje prostorje japonskega avantgardnega gibanja v šestdesetih letih dvajsetega stoletja*
}

\author{
Klara HRVATIN**
}

\section{Izvleček}

Eno ključnih dogajanj v široki paleti japonske avantgardne umetnosti v zgodnjih šestdesetih letih dvajsetega stoletja je proizvedlo umetniško gibanje Sōgetsu (Sögetsu geijutsu undō 草月芸術運動). To je od svojega začetka leta 1958 skoraj desetletje in pol ponujalo bogat eksperimentalni in inovativni prostor japonske umetnosti. Raziskovanje in arhiviranje fenomena tega gibanja in njegovega skupnega prostora (umetniškega centra Sōgetsu) sega $\mathrm{v}$ začetek enaindvajsetega stoletja, medtem kot je spletno mesto in participatorno spletno objavo dobilo šele leta 2013.

$\mathrm{S}$ kvalitativno raziskovalnim pristopom (predvsem neformalnega in pol-strukturiranega intervjuja) članek ponazarja, kako lahko gledamo na prostorje umetniškega gibanja Sōgetsu in ga definiramo. Upošteva predvsem načine arhiviranja ter (re)produkcije nekaterih glavnih del, značilnih za gibanje. Članek prikaže, kako je to prostorje v konfliktu $\mathrm{z}$ osnovnimi koncepti gibanja $\mathrm{v}$ šestdesetih letih, med katerimi sta bila med glavnimi eksperimentalni duh in meddisciplinarno sodelovanje, in kako lahko to prostorje vidimo z vidika današnjega koncepta potrošništva.

Ključne besede: umetniško gibanje Sōgetsu, prostorje, umetniški center univerze Keio, MoMA post, Toshi Ichiyanagi

Pričujoči prispevek je sofinancirala Javna agencija za raziskovalno dejavnost Republike Slovenije (ARRS) iz državnega proračuna v okviru raziskovalnega projekta »Konfucijanska prenova in teoretske osnove kitajske modernizacije« (ID J6-6845). Skrajšana verzija teme tega članka je bila uspešno predstavljena na mednarodni konferenci Cultural Typhoon in Europe 2016 (22.-25. 9., Department of East Asian Studies, University of Vienna). Članek je prav tako nadgrajen s karikaturnimi ilustracijami v sodelovanju s karikaturistom Ehssanom Sakhaeejem. Ehssan Sakhaee je karikaturist, pedagog, filozof in inženir; kot profesor zaposlen na Univerzi $\mathrm{v}$ Sydneyu (Faculty of Engineering and Information Technologies) in inštruktor v ustanovi UCLA Extension.

** Klara HRVATIN, Dr., Asistentka in lektorica, Oddelek za azijske študije, Univerza v Ljubljani, Slovenija. klara.hrvatin[at]ff.uni-lj.si

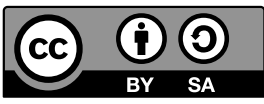




\title{
Places and Spaces as Cultural Production - Reflection on Today's Place and Space of the Japanese Avant-garde Movement of the 1960s
}

\begin{abstract}
The Sōgetsu art movement (Sögetsu geijutsu undō 草月芸術運動) turned out to be one of the key happenings in the wide palette of Japanese avant-garde art in the early 1960s. With its start in 1958, for almost decade and a half it provided a rich experimental and innovative space for Japanese art. The research and archiving of the phenomenon of the movement and its common venue started at the beginning of the twenty-first century, and only obtained its online resource and a participatory platform in 2013.

Through qualitative research (semi-structured interviews, informal interviewing), this article illustrates how we can look on and define today's place and space of the Sōgetsu art movement, taking into consideration especially the ways of archiving and (re)production of some of the main works which were born out of the movement. It gives an insight into how those places and spaces were in conflict with the main concept of the movement in the 1960s, among which the experimental spirit and the cross-disciplinary cooperation were two leading ideas. It also touches upon the question of how those places and spaces could be seen in the relation to the nowadays inevitable aspect of consumption.
\end{abstract}

Keywords: the Sōgetsu art movement, places and spaces, University Keio art center, MoMA post, Toshi Ichiyanagi

Takrat so bila čudovita, toda $\mathrm{v}$ tem obdobju ta dela nimajo enakega pomena. Umetnost iz šestdesetih let je postala kvalificirana in akademski svet jo je dodobra prečesal. In če ljudje iz šestdesetih let prejšnjega stoletja ponavljajo ta dela in pridobivajo oblast nad njimi, je to dolgočasno dejanje. (Takahashi v Hrvatin 2012, 61)

\section{Uvod v umetniški center Sōgetsu: Koncepti in aktivnosti}

Čeprav se zdi, da je šlo le za umetniško prizorišče oziroma prostor, kjer je potekalo veliko umetniških aktivnosti, moramo poudariti, da kadar govorimo o umetniškem centru Sōgetsu ali Centru ${ }^{1}$ (Sögetsu àto sentā 草月アートセンター), z njim impliciramo umetniško gibanje Sōgetsu (Sōgetsu geijutsu undō 草月芸術運 動), katerega osrednji prostor je bil Center (Yūji Takahashi, v pogovoru z avtorjem, 19. februar 2011). Kot eden ključnih v široki paleti avantgardnih gibanj v zgodnjih šestdesetih letih dvajsetega stoletja je skoraj desetletje in pol ponujal bogat eksperimentalni in inovativni prostor japonski umetnosti.

1 Skrajšano za umetniški center Sōgetsu. Prav tako v članku avtorica za skrajšano obliko zapisa umetniškega centra Sōgetsu uporablja kratico SAC. 
Aktivnosti in združenja, ki so potekali pod okriljem gibanja, presegajo današnje ozko in strogo parceliranje umetnosti v samostojne prostorčke bodisi glasbe bodisi likovne umetnosti bodisi grafičnega oblikovanja etc. Gibanje odseva duha tistega časa v japonski umetnosti, ko sta bila v ospredju meddisciplinarno in eksperimentalno sodelovanje (tako na nacionalni kot internacionalni ravni) med umetniki z različnih umetniških področij. Danes povsod prepoznavni umetniki so bili aktivni $\mathrm{v}$ tem gibanju oziroma so $\mathrm{v}$ njem s sodelovanjem na različnih področjih začenjali svojo pot. Hiroshi Teshigahara, direktor Centra, naslednik očetove šole ikebane sloga Sōgetsu, je krepko posegel v hierarhijo filmskih velikanov in pokazal drugačna pota takratnemu mehanizmu filmske industrije. Svoje ideje je združil z dramatikom Kōbōjem Abejem in skladateljem Tōrujem Takemitsujem in tako so na dan prišli filmi, ki so začeli pot neodvisnega filma. ${ }^{2}$ Takšnih in drugačnih sodelovanj je bilo sicer nešteto. Tōru Takemitsu je ogromno sodeloval tudi z grafičnim oblikovalcem Kōheijem Sugiuro pri realizaciji t. i. grafičnih notacij, z ilustratorjem Yōjijem Kurijem na glasbeno-ilustratorskem platnu in še bi lahko naštevali.

Sodelovanja umetnikov so zapolnjevala mnogovrstne aktivnosti, ki si jih je Center zastavil kot reprezentativne. Težko bi opredelili, katere so bile najpomembnejše, je pa večina aktivnosti pripadala oz. se v grobem delila na eksperimentalne koncerte, recitale nove sodobne glasbe ter predstave eksperimentalnih filmov in animacij (t. i. Sōgetsu Music Inn, Sögetsu Contemporary Series, Sögetsu Cinematheque); glasba je prednjačila od 1958. do 1965., medtem ko so po tem obdobju prišli v ospredje film, animacija in t. i. underground gledališče.

Samo delovanje umetnikov oz. Centra je spodbujalo inovativnost, eksperimentiranje, idejo sodelovanja (t. i. kolektivizma) ter celostne ali totalne umetnine (sōgō geijutsu). Pozornost je vzbujalo tudi sodelovanje s tujimi umetniki. Sledili so idejam, ki so nasprotovale vrednotenju umetnosti, kakršno je takrat prevladovalo $\mathrm{v}$ družbi. V primerjavi z vplivi serializma in konkretne glasbe, vidnih v zgodnejših avantgardnih gibanjih (glej Hrvatin 2016), je Center odprl novo pot hepeningu, dogodkom, različnim oblikam skupinske improvizacije, multimediji in konceptualni umetnosti (Everett 2009, 189). Kot osrednji koncept, ki se je sprva iz glasbenih dejavnosti razširil na celoten spekter umetniških del v Centru, je pomembno opozoriti na nedoločenost, ki sta jo na Japonsko ponesla Toshi Ichiyanagi in John Cage.

O gibanju in njegovih dogodkih najbolje priča katalog razstave Soggetsu to Sono Jidai (1945-1970), ki sta ga leta 1998 izdala Mestni muzej umetnosti Ashiya (Ashiya Shiritsu Bijutsu Hakubutsukan) in Mestni muzej umetnosti Chiba

2 Zanimiv je tudi njihov filmski manifest, $\mathrm{v}$ katerem se odvračajo od filmske industrije in $\mathrm{v}$ ospredje postavljajo kolaborativni pristop do filma ter v nasprotju s filmsko industrijo $\mathrm{v}$ tistem času gledajo na film kot na celostno umetnost. 
(Chibashi Bijutsukan). Med drugim je zanimiva tudi pred nekaj leti izdana publikacija Produkcijski zapiski (Purodakushon nōto, 2007), ki izčrpno prikazuje samo delovanje in sodelovanje umetnikov pri nastajanju predvsem neodvisne filmske produkcije gibanja. Raziskovanje ter arhiviranje gibanja se je sicer začelo dokaj pozno, kot smo že omenili; šele leta 2013 je pridobilo spletno mesto in participatorno spletno objavo.

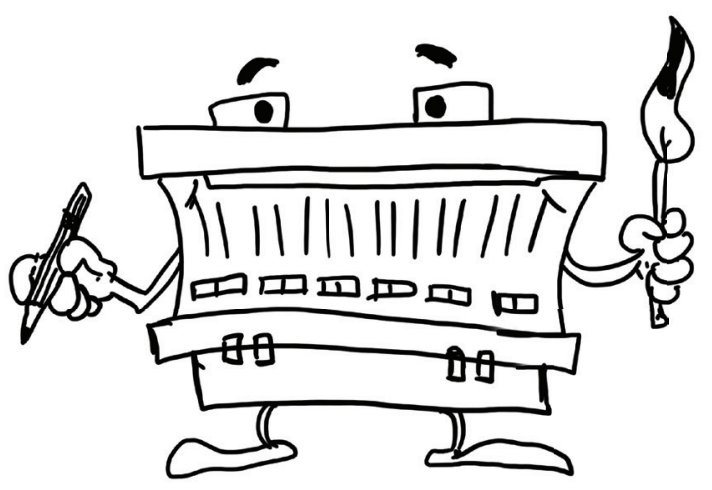

Ehssow

Karikatura 1: Umetniški center Sögetsu (1958-1971) kot multi-umetniški prostor (Vir: Ebssan Sakhaee)

Avtorica bo v članku definirala današnje prostorje gibanja skozi prizmo predvsem kvantitativne metode raziskovanja, $\mathrm{v}$ prvi vrsti $\mathrm{z}$ neformalnim, pol-strukturiranim intervjujem $z$ arhivisti gibanja ter $z$ njegovimi umetniki. Že od leta 2008 spremlja arhiviranje samega gibanja, kar zajema obdobje pred prvo objavo spletnega mesta o samem gibanju (ki jo je omogočil umetniški center Keio) ter prav tako obdobje pred participatorno spletno objavo, ki jo je napravil muzej MoMA (leta 2013). Poleg metode obdelovanja literature ter analize virov na temo gibanja Sōgetsu, obiska in analize arhivskega materiala gibanja Sōgetsu (tako v umetniškem centru Keio kot tudi v arhivu centra Sōgetsu) so ji neformalni in pol-strukturirani intervjuji ter osebna korespondenca $\mathrm{z}$ arhivisti omogočili vpogled $\mathrm{v}$ njihovo aktualno delo, načine arhiviranja ter (re)produkcije nekaterih glavnih del, značilnih za gibanje.

Arhiviranje gibanja določa pomembno prostorje gibanja. Poleg arhiviranja bo prikazano tudi drugo potencialno prostorje gibanja, ki ga zaznamuje vse pogostejša reprodukcija del iz gibanja ter izdajanje glasbe, prvotno posnete v umetniškem centru Sōgetsu, ki je na plano prišla v zadnjem času. Koliko relevantno je to prostorje in kakšen odnos imajo do njega umetniki-člani gibanja? Tudi v ta namen bodo uporabljeni pol-strukturirani intervjuji in intervjuji, tokrat s še živečimi 
umetniki iz obdobja gibanja, predvsem z glasbenikom Yūjijem Takahashijem ter grafičnim oblikovalcem Kōheijem Sugiuro.

Raziskovanje samega gibanja in njegovo arhiviranje je še vedno precej mlado. Članek želi predvsem osvetliti današnje prostorje gibanja, ki se je izoblikovalo na začetku enaindvajsetega stoletja, pri čemer je njegov namen opozoriti na morebitne konflikte s prvotnimi lastnostmi gibanja.

\section{Konstrukt pretekle umetnosti v sedanjosti - kako je viden v prostorju umetniškega gibanja Sōgetsu}

Seveda je umetniško gibanje Sōgetsu že obrodilo sadove in se vpisalo v zgodovinsko beležnico umetniških gibanj (čeprav je trajalo nekaj desetletji, da je prišlo na plan), vprašanje pa je, kako ta produktivna in zanimiva preteklost živi danes, obkrožajoč naša življenja? Kaj se zgodi, kako zaznamujemo zanimivo zgodovino $\mathrm{v}$ današnjem času, ki ima v primerjavi z letom 1960 drugačna kulturna izhodišča, visoko razvito informativno tehnologijo, drugačno delovanje trga, političnega sistema, globalizacije, močnejšo institucionalizacijo etc.?

\section{Novi pristopi k arhiviranju: Umetniški center univerze Keio in MoMA}

Instituciji, ki sta danes v veliki meri odgovorni za gradivo o gibanju, med drugim ga shranjujeta in sta sodelovali pri oblikovanju podatkov za spletno objavo, sta arhiv dvorane Sōgetsu, ki ima svoj prostor znotraj stavbe šole ikebane sloga Sōgetsu, ter t. i. RCAAA (krajše za Archives at Research Center for the Arts and Arts Administration ali Arhiv raziskovalnega centra za umetnost in umetniško administracijo $^{3}$ na univerzi Keio oz.v umetniškem centru univerze Keio, ki je odgovoren za precejšen del arhiva umetniškega gibanja Sōgetsu.

$\mathrm{V}$ arhivu dvorane Sōgetsu (ta stoji na istem mestu, kjer je bil sedež gibanja in kjer je bilo še pred kratkim edino mesto arhiviranja), je v knjižnici shranjen le še skromen delček dokumentov, kot so:

a) arhivska knjižnica Sōgetsu, v kateri lahko najdemo tako knjige kot revije v povezavi s SAC-om;

b) fotografski material: izčrpna kolekcija fotografij in negativov, ki pričajo o zakulisju filmskega ustvarjanja, obiskov tujih umetnikov itd.;

3 V zadnjem času je aktualno urejanje arhivov velikanov japonske umetnosti, kot so Hijikata Tatsumi, Takiguchi Shūzō, Yui Shoichi, Nishiwaki Junzaburō in drugi. 
c) vabila mednarodnim skladateljem (Kokusai Sakkyokuka Shōtai);

d) posterji, brošure ter vabila (v obliki razglednic) na prireditve v okviru samega SAC-a;

e) partiture oziroma deli partitur, shranjenih in v lasti $\mathrm{SAC}-\mathrm{a}$;

f) fotokopije časopisov ter člankov, povezanih z dogajanji v SAC-u,

g) glasbeni posnetki na kasetah ( $S A C T e-p u)$ celotne glasbe, ki je bila posneta $\mathrm{v}$ Centru: 266 primerov iz obdobja od leta 1960 (2.16) do leta 1964 (5);

h) redek video material;

i) kopije revij SAC (SAC Journal), ki jih je Center izdajal.

V tako imenovanem kotičku ikebana plaza, tudi znotraj dvorane Sōgetsu, prodajajo tako revije kot knjige na temo šole ikebane Sōgetsu, poleg tega lahko najdemo nekaj katalogov in brošur ter knjig ${ }^{4}$ tudi na temo dogodkov v Centru.

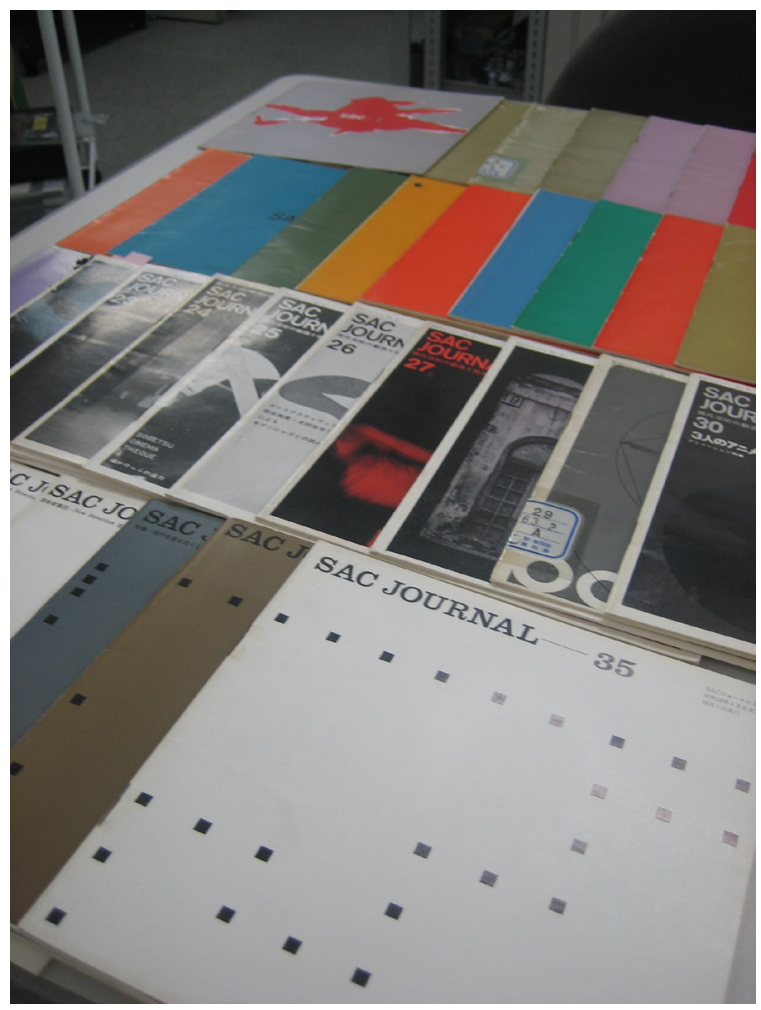

Slika 1: SAC Journal - publikacija Centra (izarbiva umetniškega centra Keio) (Vir: avtorica)

4 Predvsem gre za literaturo, ki jo je drugače težko najti v prosti prodaji. Takšni so na primer Production note (glej bibliografijo) ali pa katalogi s samih razstav v Centru (Yoko Ono "Fumie« ter »Beyond the seeing - Visualized Characters and music«). 
Več gradiva v povezavi s SAC-om, kot ga je najti v sami arhivski knjižnici dvorane Sōgetsu, je danes arhiviranega in shranjenega na univerzi Keio, v arhivu RCAAA. Precejšen del gradiva (čeprav ne vsega, kot je jasno iz prejšnjega odstavka) je dvorana sama zaupala v oskrbo in shranjevanje univerzi Keio. Kronološko je klasificirano v naslednjem zaporedju:

1) SAC Journal - publikacija Centra, sprva imenovana SAC,

2) Sōgetsu Music Inn - eksperimentalni jazz koncerti,

3) Sōgetsu Contemporary Series - recitali sodobne glasbe,

4) Sōgetsu Cinematheque 1-4 - animacija in eksperimentalni film in

5) Sōgetsu Chronological 1-5 (Kronologija Sōgetsu 1-5).

Prav tako je omenjeni center z gradivom, ki ga je dobil v začasno uporabo od arhiva dvorane Sōgetsu, oblikoval pregleden časovno-linearni zemljevid vseh dogodkov Centra, ki so razvidni iz shranjenih artefaktov. Prenesli so ga tudi na spletno mesto oziroma so zanj oblikovali spletno mesto na internetni strani arhiva umetniškega centra univerze Keio. Kasneje je bil prestavljen oziroma pripet na t. i. participatorno spletno stran muzeja moderne umetnosti MoMA, imenovano post - notes on modern and contemporary art around the globe, $\mathrm{v}$ sklopu projekta C-MAP (Contemporary Modern Art Perspective). Post svoj spletni prostor v prvi vrsti posveča moderni in sodobni umetnosti zunaj glavnih oblikovalcev smernic umetnosti (Severne Amerike in Zahodne Evrope) in kliče k prispevkom tako posameznikov kot institucij z vsega sveta. (post 2013)

Post je zasnovan kot participativna platforma. Ko ustvarite ID uporabnika, lahko kdorkoli na spletnem mestu objavlja komentarje, besedila, slike in videoposnetke. Če želite začeti, kliknite zavihek »SIGN UP«. Če se želite pridružiti pogovoru, kliknite gumb »DISKUSIJE«, ki se pojavlja skozi celotno spletno mesto. Izberite "FOLLOW « na desni strani vsake spletne strani, če želite dodati posodobitve, ko dodate nove materiale, ki se nanašajo na vaše interese. (ibid.)

In čeprav vse skupaj spominja na okence Facebooka, oziroma na neke vrste "akademski Facebook", je s tem gibanje leta 2013 prvič dobilo novo, moderno prostorje in tako razširilo svoj tematski sklop na spletnem portalu ter opozorilo publiko na obstoj in pomembnost umetniškega centra Sōgetsu.

Začetek pred aplikacijo posta pa je predstavljalo postavljanje baze podatkov s pregledom vseh aktivnosti oziroma vseh planiranih dogodkov, orisanih glede na ohranjeni natisnjeni material (vključno s fotografijami dogodkov, vabil, posterjev, brošur, etc.) arhiva dvorane Sōgetsu, ki se ga je intenzivno lotila skupina kustosov umetniškega centra Keio. 


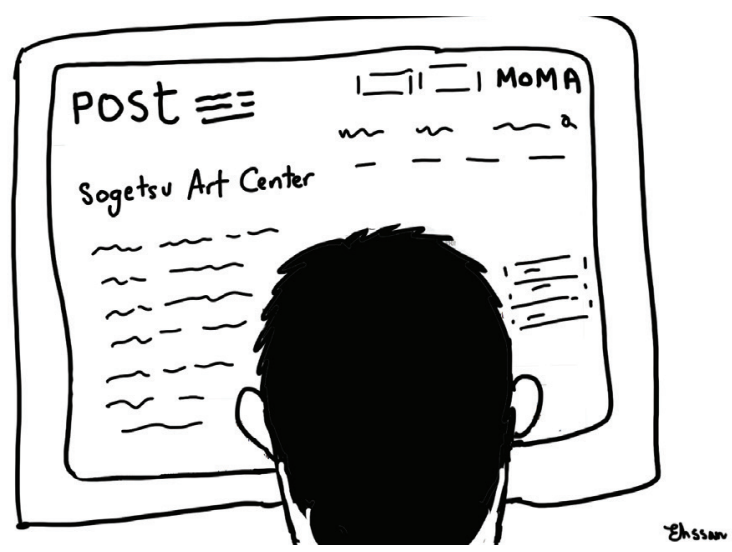

Karikatura 2: Post-današnje prostorje gibanja Sögetsu (Vir: Ehssan Sakhaee)
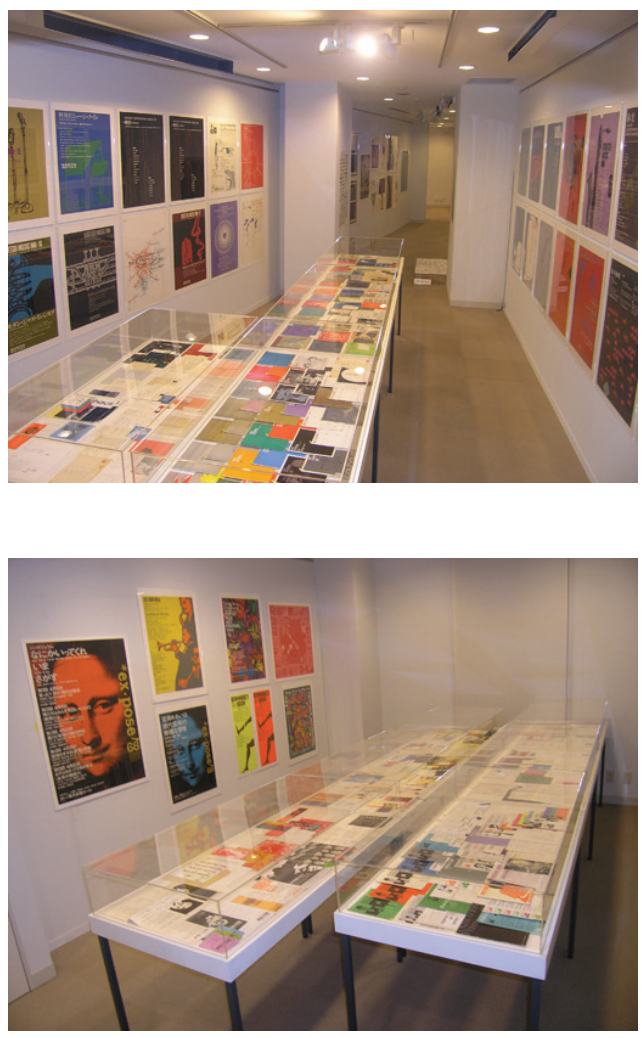

Sliki 2 in 3: Prva pregledna razstava posterjev in drugega obranjenega materiala, ki priča o dogodkih v umetniškem centru Sögetsu (umetniški center Keio (KUAC) univerze Keio, Into the Penumbra of Printed Matter: Sōgetsu Art Center, 1958-1971) (Vir: Sen Uesaki) 
Pionirsko so digitalizirali shranjene »dokaze« vseh dogodkov (v obliki časovne linije), za katere so imeli ohranjene dokumente (Slika 4). Za urejanje samega materiala sta odgovorna predvsem kustosa Hitoshi Kubo in Uesaki Sen, od leta 2011 pa Uesaki Sen ${ }^{5}$ (Kubo Hitoshi, osebno sporočilo avtorju, 15. september 2017). Leta 2009 sta v sklopu umetniškega centra univerze Keio sprva organizirala razstavo Into the Penumbra of Printed Matter: Soggetsu Art Center, 1958-1971 (草月アート センター—印刷物という『半影』), Mining Art Resources Minato and Keio University Art Center, 2009, ki je bila prva razstava vseh ohranjenih natisnjenih dokumentov o gibanju (Sliki 2 in 3).

Med drugimi dogodki omenimo še simpozij z naslovom Projecting Against Sögetsu Art Center and its Archives leta 2011. Kustos Sen Uesaki je v zbirko arhiviranega gradiva želel vključiti nove načine arhiviranja oziroma obujanja samega materiala, na primer ponovno izdajanje publikacije SAC Journal, ki so jo izdajali v času gibanja. Zadnji izmed projektov na to temo je delo Hitoshija Kuba in njegov nov koncept arhiviranja, ki ga je podprla japonska agencija za promocijo znanosti (JSPS).

Postopek arhiviranja spominja na postopek urejanja filma. (...) Če pogledamo na montažo arhiva malo drugače, arhivski materiali spominjajo na filmske posnetke. Ob vsakem dogodku obstajajo tri perspektive, iz katerih lahko gledamo na dogodek. Vstopnico, letak, plakat, etc. samega dogodka imenujem pro-spect dogodka (vezan na vidik dogodka pred samim dogodkom), fotografije, recenzije $\mathrm{v}$ revijah in časopisih so retro-spect (vezan na stališče dogodka po zaključku dogodka). Spomini osebe, ki je videla dogodek, so spectacle. Glede na to, kako montiramo omenjene tri perspektive dogodka, oblikujemo penumbro dogodka. (Kubo Hitoshi, osebno sporočilo avtorici, 24. maj 2016)

Koščke arhivskih filmskih posnetkov je stkal v film o režiserju Hiroshiju Teshigahari. Način dela, ki ga odseva takšno arhiviranje, je zelo inovativen, način, na katerega ga predstavlja umetniški center univerze Keio (KUAC), pa potrjuje njihovo osnovno idejo iskanja novih načinov arhiviranja:

5 Sen Uesaki (Keio University) je eden izmed vodilnih arhivarjev umetniškega centra univerze Keio (KUAC) in tudi predavatelj na tej instituciji. Ukvarja se s tematiko zbiranja in konzerviranja arhivskih materialov in hkrati predava o različnih umetniških praksah na mednarodnem nivoju s tematiko, kot je The Archival Impulse: Collecting and Conserving the Moving Image in Asia (v organizaciji Asia Art Archive, Collaborative Cataloging Japan), ter sodeluje na delavnicah, kakršna je leta 2015 potekala na univerzi Harvard Redefining Access: Archival Practice and Japanese Materials in the New Media Ecology. 
$\mathrm{V}$ ta namen se ukvarjamo s številnimi teoretičnimi študijami in praksami, ki so namenjene izpolnjevanju zahtev dobe, v kateri živimo. Zavedamo se, da živimo v informacijski dobi; obdobju, ki je označeno s hitro spreminjajočimi se vrednostmi in senzibilnostmi, za katero je značilen soobstoj pogosto protislovnih ali nasprotujočih si konceptov in praks. Sistemi, ki so nam na voljo za vključevanje takšne resničnosti, se pogosto izkažejo za neprimerne. Zato se je KUAC zavezal $\mathrm{k}$ iskanju novih modelov kulturne dejavnosti, ki se ne opirajo na uveljavljene akademske okvire, in $\mathrm{k}$ spodbujanju ustvarjalnih občutljivosti, primernih za različne sisteme vrednot sedanjega časa. Naš splošni cilj je prispevati k ustvarjanju živahnega kulturnega okolja. (Keio 1993)

Začetki samega arhiviranje gradiva o umetniškem centru Sōgetsu segajo v leto 2004, na umetniško univerzo Tama v Tokiu v sklopu zbirke Kuniharuja Akiyame. Na željo Hiroshija Teshigahare je Kuniharu Akiyama kot član umetniškega gibanja Centra prevzel odgovornost za oblikovanje arhiva Sōgetsu v novi stavbi Sōgetsu (od leta 1978). Del tega arhiva je bil tudi na Umetniški univerzi Tama. Tako Kubo Hitoshi kot Sen Uesaki sta sodelovala pri zbirki na tej univerzi, kasneje se je zbirka prenesla v umetniški center univerze Keio (Kubo Hitoshi, osebno sporočilo avtorici, 15. september 2017).

\section{Reprodukcija del umetniškega gibanja Sōgetsu}

\section{Ponovne uprizoritve}

Znano je, da je gibanje spremljala široka paleta umetniških kreacij, med katerimi jih je v zadnjem času veliko doživelo ponovne uprizoritve. Takšen primer je skladba skladatelja Tōruja Takemitsuja Mizu-no-Kyoku (水の曲). Mizu-no-Kyoku ali Glasba kapljic je bila prvič predstavljena na Takemitsujevem solo koncertu, ki je bil eden izmed koncertov v sklopu Skladateljske skupine, eni izmed zgodnjih aktivnosti Centra v seriji Sōgetsu Contemporary Series. Šlo je za prvo sodelovanje med skladateljem in tonskim mojstrom Centra Yūnosukejem Okuyamo, s katerim sta se lotila eksperimenta, kako vodne kapljice spremeniti v glasbo; posnela sta raznovrstne zvoke vodnih kapljic in jih kasneje manipulirala z električnim modulatorjem. $Z$ daljšim naslovom, ki je bil objavljen ob prvi izvedbi kompozicije, $N o \bar{o}-$ Water music (能 舞による「水の曲」Nömaini yoru mizuno kyoku), lahko delo opredelimo kot novi hibrid glasbeno-vizualne izkušnje, ki je prvotno združeval skladbo za trak, spremljavo dveh flavt in ene alt flavte, določene prostorske dispozicije instrumentov in zvočnikov, osvetljave in plesa nō s plesalcem Hisaojem Kanzejem. 
Po premierni izvedbi je bila skladba $M i z u-n o-K y o k u$ v glavnem izvajana zgolj kot glasba na traku (brez spremljave flavte in plesa) in je bila kot takšna zaigrana tudi na simpoziju Dela Hiroshija Teshigahare (1963). Sledila je izvedba na festivalu Nuova Consonanza III Festival v Rimu (1965), festivalu Festival of early electronic music in Paris (1988) in koncertu Music from Japan Concert (1997). ${ }^{6}$ Ponovno predvajanje skladbe je bilo tudi del prireditve Obuditev umetniškega centra Sögetsu (Saigen: Sōgetsu āto sentā, 再現草月アートセンタ-) ob šestdeseti obletnici šole ikebane Sōgetsu in predvsem ob trideseti obletnici samega Centra. Predvsem zanimivo pa je, da je skladba sčasoma postala tudi del repertoarja gledališča nō, kot je razvidno iz programa Narodnega gledališča nō (glej Kokuritsu 2011) v Tokiu. Seveda je to eden zanimivejših primerov, kako se je delo naprej izvajalo in nato kot glasba na traku dobilo svoje mesto v stalnem repertoarju gledališča nō.

Še eden izmed primerov kontinuirane reprize del iz časa gibanja, pri katerem pa ne gre za konkretno glasbo, je t. i. hepening istega avtorja, Blue Aurora for Toshi Ichiyanagi, iz leta 1964. Danes ga lahko slišimo v izvedbi zasedbe Blue Aurora Saxophone quartet, ki je delo pogosto izvajala v letih 2012-2013. Predhodne izvedbe vključujejo Toshija Ichiyanagija in Itoja Kena na prireditvi Projekt Takemitsu v Niigati, iz leta 2000, medtem ko je Sunao Isaji leta 2002 posnel novo različico hapeninga. Najzgodnejša verzija predstave sega v leta delovanja Centra, 1) premierna predstava Johna Cagea, 2) spet ena izmed različic izpod rok skladatelja in bobnarja Stomu Yamash'te in ena tudi od samega avtorja hepeninga Tōruja Takemitsuja.

Za delo Blue Aurora je značilno, da ni natančno določeno oziroma, če smo natančnejši, da uporablja koncept nedoločenosti. Ne vsebuje klasične notacije; ta je nadomeščena $\mathrm{z}$ abstraktno grafično notacijo, besednimi znaki, ki se uporabljajo kot njene ključne besede, ter napotki za uprizoritev. Dolžina predstave, izvajalci in prostor predstave niso opredeljeni. Če se omejimo na njeno glasbeno interpretacijo, je edino pravilo, ki ga velja pri tem upoštevati, to, da se moramo držati ključnih besed kompozicije. Izvajalci imajo na ta način svobodno možnost izvedbe, zato koncept nedoločenosti daje možnost neskončnih različnih izvedb.

\section{Izdajanje glasbe posnete prvotno v umetniškem centru Sōgetsu}

Ponovnim uprizarjanjem del se je pridružila tendenca izdajanja CD-jev z glasbenimi posnetki. Ena najzanimivejših je v zadnjem času kompilacija glasbenih del, ki je bila prvotno posneta v umetniškem centru Sōgetsu, iz časa samega gibanja, oz. izdaja originalnih posnetkov, ki jih še vedno hrani dvorana Sōgetsu. John Cage

6 Za podrobnosti glej Siddons (2001, 104); Kawasaki (2009, 1069-70). 
- John Cage Shock Vol. 1 (2012) ter John Cage - John Cage Shock Vol. 3 (2012) reprezentirata zvok tedanjega Centra, s poudarkom na t. i. Cageevem šoku, in predstavljata premierne kompozicije Johna Cagea, Christiana Wolfa, Tōruja Takemitsuja in Michaela von Biela v izvedbi Davida Tudorja, Yūjija Takahashija, Kenjija Kobayashiya in Toshija Ichiyanagija.

Posnetki nudijo slušni vpogled v leto 1962 (meseca oktobra), obisk Johna Cagea in Davida Tudorja v umetniškem centru Sōgetsu. V spremnem programu CD-ja prepričljivo opozarjajo na to, da gre za »velik zgodovinski zaklad« (Forced 2017), ki je »ostal skrit in neslišan pol stoletja, vendar ostaja nespremenjen« (ibid.). $\mathrm{Ne}$ pozabimo, da vsebuje tudi redke fotografije in spremno besedo $\mathrm{v}$ angleščini in japonščini s komentarji odločilnega skladatelja pri prenosu del Johna Cagea na Japonsko, Toshija Ichiyanagija.
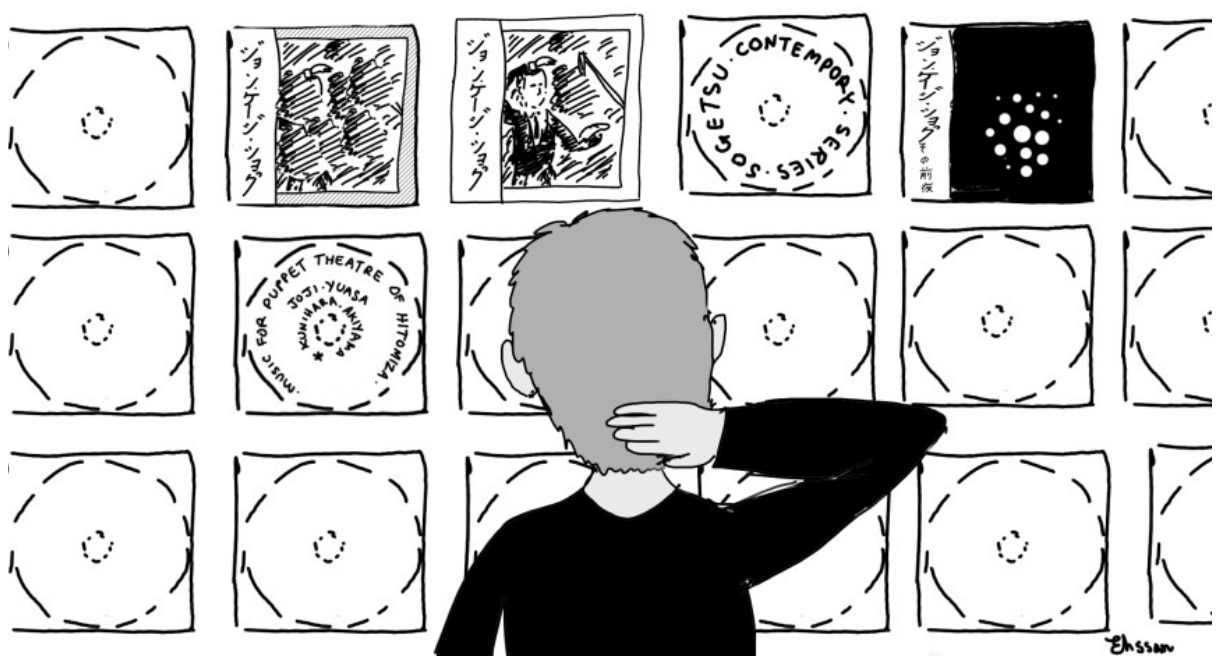

Karikatura 3: Pospešena tendenca izdajanja glasbe umetniškega centra Sögetsu (Vir: Ehssan Sakhaee)

V isto skupino spadajo tudi CD-ji iz serij Sögetsu contemporary series, številka 14: Duo recital Toshija Ichiyanagija in Keijija Kobayashija, ki nosi naslov Noč pred Cageevim šokom (The night before John Cage shock), iz leta 2016. Tudi ta CD v svojem naslovu uporablja popularizacijo Cageevega šoka, tokrat naznanja dogodke pred samim nastopom Cagea na Japonskem; recitalom Toshiya Ichiyanagija ter Kenjija Kobayashija.

Ena izmed sklad na CD-ju je Pile, za katero je Toshi Ichiyanagi uporabil metodo igranja na notranji del klavirja, skupaj z glasom Yoko Ono, njegove takratne žene. 
Šlo je za takrat prvo in edino delo, ki je pri svoji izvedbi uporabljalo živo elektroniko. (Omega 2015) Delo je tudi dandanes pogosto ponovno izvajano v živo.

Omenimo lahko tudi zgodnejšo serijo enaindvajsetih CD-jev z naslovom Nepoznana japonska glasba (Obscure Tape Music OfJapan), med katerimi je veliko del, ki so jih predvajali v Centru, kot so Glasba za lutkovno gledališče Hitomi-za (Obscure Tape Music of Japan, vol. 2), posnetki eksperimentalne lutkovne skupine, ki je leta 1962 nastopila na odru umetniškega centra Sōgetsu, glasbena drama Rdeči Kokon (Akai Mayu) skladatelja Makotoja Moroija in Kuniharu Akiyame (Obscure Tape Music of Japan, vol. 2), Makoto Moroi / Kuniharu Akiyama - Music Drama Akai Mayu ter številna druga. Izdajanje CD-jev iz te serije sega v leto 2004 in se še vedno dopolnjuje. Pred letom 2004 verjetno tako rekoč nismo imeli tako populariziranega dostopa do glasbenih posnetkov gibanja. Nekaj kompozicij je bilo zbranih v posameznih albumih skladateljev, sama ozaveščenost o gibanju ter glasbi iz gibanja pa še ni bila v ospredju.

\section{Konflikti med »tedaj« in "zdaj«}

Iz oblik, v katerih se danes izrisuje prostorje umetniškega Centra, je razvidno, da se je oblikovala skupina, ki je začela ter tudi nadaljuje oživitve del iz šestdesetih let. $V$ veliki večini ta poteka pod taktirko skladatelja Toshija Ichiyanagija, ki je bil eden vodilnih pri samem gibanju, ter prav tako v sodelovanju še z nekaterimi bivšimi člani gibanja, kot so Takehisa Kosugi, Mieko Shiomi in drugi. Posredno ali neposredno so odgovorni za današnje recepcije gibanja, med drugim za večino ponovnih uprizoritev, prav tako pa so gonilna sila in avtoriteta ponovnega izdajanja glasbe. Seveda so se izoblikovale tudi skupine drugih umetnikov, ki izvajajo njihova dela. Vzemimo na primer prireditev k razstavi Art, Anti-Art, Non-Art: Experimentations in the Public Sphere in Postwar Japan, 1950-1970 - imenovani Works by Ichiyanagi, Kosugi, Ono, and Shiomi (Večer del Ichiyahagija, Kusugija, Ono, in Shiomi), na kateri so se glasbeniki Rhodri Davis, Jeremy Drake, Rich West in drugi posvetili obujanju svojih del iz tega obdobja. ${ }^{7}$

Med smernicami prvotnega gibanja ter njegovega obujanja in oživitve je pomembno poudariti tisti, ki ju med današnjo prezaposlenostjo $\mathrm{z}$ ideologijami rekreacij in reformacij svet umetnosti neštetokrat spusti skozi rešeto svojih ideoloških poslanstev.

Koncepti gibanja oz. obdobja gibanja. Obstaja glaven trk oziroma dihotomija v pristopih, ki jih je zagovarjalo gibanje $\mathrm{v}$ šestedesih letih, in tem, kar dandanes

7 Glej Rajikaru concert program. 
"prodajamo« iz takratne zakladnice. Poglejmo si moto samega gibanja/umetniškega centra Sōgetsu, ob katerem nam postane jasno, da "prodajamo« ravno to, proti čemur se je gibanje bojevalo s svojim delovanjem.

Cilj centra je bil zagotoviti prostor umetnikom iz različnih umetniških zvrsti, da bi se zbirali in ustvarjali, prikazovali in kritizirali drug drugega brez kakršnih koli omejitev. Sistem, v katerem umetniki kreirajo svoje delo, je v ospredje postavljal kreativnost in se zavzemal za zaščito umetnikov in njihovih kreacij pred komercializmom. (Soggetsu o shiru)

Ne smemo pozabiti, da gre za gibanje, ki se je odlikovalo po dokumentarnem filmu, prvo, ki je prineslo eksperimentalni film Japonski, koncerte žive elektronske glasbe, grafično notacijo, popularizacijo podzemnega filmskega svetu itn. In avantgardno gibanje se je prvotno navezovalo izključno na tiste umetnike, ki niso pripadali uveljavljenim umetniškim organizacijam, ali pa na dela, ki so uporabljala nekonvencialne sloge ali medije.

Koncept narave dela. Dela, ki so bila v osnovi zgrajena skupinsko/kolektivno (do te mere, da je bilo včasih težko določiti avtorja) in so bila eksperimentalna v svoji osnovi, so sedaj urejena in izdana pod določenim imenom. Izgubijo naravo dela, $\mathrm{v}$ kateri so bila narejena, ter značilnosti svojega prvotnega bitja (obstoja).

Eden osnovnih konceptov, ki je vplival na gibanje, je koncept nedoločenosti. Pri glasbeni izvedbi je to pomenilo kompozicijski postopek, v katerem so nekateri aspekti glasbenega dela prepuščeni naključju oziroma svobodni izbiri interpreta. Vsakič ko se je določeno glasbeno delo izvedlo, je bilo drugačno, ali, bolje rečeno, se je kontinuirano spreminjalo skozi proces izvedbe dela. Tako sta delo in njegova uprizoritev izgubila pomen »določenosti« in pustila veliko možnosti izvedbe (čeprav sta vsebovala nekaj določil, ki jih je bilo treba upoštevati). Podoben proces je bil viden tudi pri samih nastankih del oziroma je nedoločenost prinesla prav tako manj posredovanja skladateljeve volje v sam zvok (Jež 2015, 78).

Umetnina, ki je sledila nedoločenosti, je bila ob vsaki ponovni uprizoritvi uprizorjena drugače in je kot takšna »živela naprej«. Enako je veljalo za hepening, eno osrednjih oblik na odru Centra predvsem in tudi kot del avantgardne umetniške kolaborative Fluxusa, ki je bil viden kot oblika t. i. dejavne (aktivne) umetnosti.

Hepeningi so ena od umetnostnih dejavnosti, ki se lahko izogne neizogibni smrti v stiku z javnostjo, h kateremu je obsojena vsa druga umetnost, saj nikoli ne morejo biti preveč izpostavljeni, ker so zasnovani le za kratek čas; mrtvi so, dobesedno, vsakič, ko se zgodijo (Kaprow 1968, 2). 
Ta koncept je ponazarjal nekaj povsem drugega od standardiziranja umetniških oblik ter prav tako zaključenih oblik izdajanja in objavljanja osrednjih del, ki so se rodila iz gibanja. Glede na to so rekonstrukcije (vsakršne re-...) del, čeprav nanje lahko gledamo tudi z veliko pozitivnih stališč, nesmiselne oziroma nas današnja oživitev gibanja, predvsem ponovna oživitev ter izdajanje glasbe (verjetno prav tako partitur), ne zadovolji.

Kar se zgodi, ko se srečamo z deli iz obdobja avantgardnega gibanja Sōgetsu, je, da ob poslušanju teh del, njihovih predstavitvah oziroma ponovnih izidih, ostanemo brez procesa dela; oziroma bolje rečeno bistva/duše dela, ki je pravzaprav igralo pomembno vlogo v tistem času. Sam produkt umetniškega dela, katerega rezultat je bil pripisan konstantnim spremembam ob vsaki izvedbi, je bil drugotnega pomena.

In kaj naj bi na oživitev gibanja porekli nekateri še živeči glavni predstavniki gibanja? Verjetno bi se lahko izoblikovali dve močni skupini: ena bi bila sestavljena iz skladateljev, ki so aktivno udeleženi v samo oživitev gibanja oziroma so njegovi privrženci, medtem ko lahko pri nekaterih izmed glavnih predstavnikov gibanja opazimo nasprotovanje takšnim akcijam. Yüji Takahashi, eden od treh najznačilnejših avantgardnih skladateljev Japonske, ni privrženec današnjega oživljanja aktivnosti (Yūji Takahashi, v pogovoru $\mathrm{z}$ avtorjem).

Takrat so bila dela čudovita, toda $\mathrm{v}$ tem obdobju nimajo enakega pomena. Umetnost iz šestdesetih let je postala kvalificirana in jo je akademski svet dodobra prečesal. In če ljudje iz šestdesetih let prejšnjega stoletja ponavljajo ta dela in pridobivajo oblast nad njimi, je to dolgočasno dejanje. (Takahashi v Hrvatin 2012, 61)

V svojem razmišljanju se mu pridružuje tudi eden izmed grafičnih oblikovalcev gibanja, Kōhei Sugiura, ki ne vidi zadostnega pomena ne vrednosti v skladateljevih sedanjih aktivnosti (Kōhei Sugiura, v pogovoru z avtorjem). Poudarja tudi, da je tisto, kar dela prav tako zgubijo s prenosom v sedanjost, šok ali presenečenje, ki so ga povzročala nekdaj (ibid.).

\section{Zaključek}

Umetniško gibanje Sōgetsu je z začetkom dvajstega stoletja razvilo novo prostorje: priča smo izbruhu založniških in akademskih stvaritev na temo gibanja, novim pristopom arhiviranja umetniškega centra univerze Keio, ki so v sodelovanju z muzejem moderne umetnosti MoMA pripeljali tudi do prve spletne participatorne objave na temo gibanja (post), valu oživitvam umetniških del iz obdobja ter 
prvih izdaj posnetkov iz glasbenih zakladnic samega prostora gibanja, umetniškega centra Sōgetsu.

Avtorica opozarja na dihotomijo med vidiki, ki jih je zagovarjalo gibanje v šestdesetih letih oziroma ki so gibanje odlikovali, ter današnjim procesom obujanja preteklih del gibanja in založništva glasbe iz obdobja gibanja. Ti s svojo pojavnostjo negirajo koncepte in naravo dela, ki so imeli velik pomen pri nastanku teh del. Predvsem velja opozoriti na koncept nedoločenosti in proces nastanka samih del, ki sta s takšnimi načini oživljanja del iz obdobja negirana in zapostavljena. Pridružuje se umetnikom, nekaterim od še živečih predstavnikov gibanja, kot so Yūji Takahshi in Kōhei Sugiura, ki v obujanju del iz obdobja ne vidijo tehtne vrednosti.

$\mathrm{Na}$ koncu verjetno velja, da je današnje prostorje umetniškega centra Sōgetsu tesno povezano $z$ današnjo družbo in njenimi aspekti potrošništva. Verjetno bo počasi oziroma sčasoma to gibanje zraslo v nekaj čisto drugačnega od svojega izvirnika; še en "artikel na policah" potrošniške sheme ali še en primer, kako je potrošništvo umetnosti (in ne razumevanje umetnosti) postalo dober prijatelj reprodukcije/produkcije umetniških del. Po temu sodeč so arhivisti, kot sta Sen Uesaki in Kobo Hitoshi s svojim naprednim in izvirnim delom, ki na boljše načine poudarja tudi same lastnosti preteklih del in opozarja nanje, še vedno v prednosti pred reprodukcijo in ponovnim objavljanjem del, tako da lahko njihovo delo označimo kot bolj produktivno od drugih poskusov oživljanja gibanja. Danes želimo določiti produkt, bodisi v smislu glasbene notacije bodisi ponovnih izidov glasbenih del, na način, ki ga želimo prodati. Nujno pa je treba opozarjati in prikazovati proces dela, ki stoji za samim delom in je bistven za razumevanja dela in gibanja - to pa je lahko tudi ena naših akademskih nalog.

\section{Viri in literatura}

Ashiya Shiritsu Bijutsu Hakubutsukan in Chibashi Bijutsukan, ur. 1998. Sōgetsu to Sono Jidai 1945-1970 草月とその時代 1945-1970 (Sōgetsu in njegovo obdobje, 1945-1970). Katalog razstave. Kobe shi: Sōgetsu to Sono Jidaiten Jikkō Iinkai.

Discologs: Obsure Tape Music from Japan. 2017. Dostop 10. september 2016. https:// www.discogs.com/Joji-Yuasa-Kuniharu-Akiyama-Music-For-Puppet-Theatre-Of-Hitomi-Za/release/726337?ev=rr.

Everett, Yayoi O. 2009. "Scream Against the Sky: Japanese Avant-garde Music in the Sixties." V Sound Commitments, Avant-garde Music and the Sixties, uredil Robert Adlington, 187-209. New York: Oxford University Press.

Forced exposure. 2017. "John Cage: John Cage Shock, vol. 1." Dostop 13. september 2016. http://www.forcedexposure.com/Catalog/EM.1104CD.html. 
Hrvatin, Klara. 2012. “Eiga Otoshiana nikansuru Takahashi Yūji tono taiwa 映 画『おとし穴』に関する高橋悠治との対話 (Takemitsu's Otoshiana throught the Eyes of Yūji Takahashi)." Handai Ongakugakubō 10: 57-63.

—. 2017. 'Ko bom velik, bom umetnik.' Eksperimentalni peskovnik japonske avantgarde." Asian Studies 5 (1): 243-270. doi: 10.4312/as.2017.5.1.243-269. Kagayake 60-nendai: Sögetsu Áto Sentā no Zenkiroku 輝け60年代 - 草月ア一ト センターの全記録 (Zlata 60. leta: Celotni arhiv Umetniškega centra Sōgetsu). Tokyo: Filmart-Sha.

Kaprow, Allan. 1968. "On happenings." Arts in Society: Happenings and Intermedia 5 (2): 28-37.

Kawasaki, Kōji. 2009. Nihon no denshi ongaku 『日本の電子音楽』 (Japanese Electronic music). Tokyo: Aiiku-sha.

Keio Daigaku Āto Sentā 慶應義塾大学アートセンター (Umetniški center univerze Keio). 1993-1917. “About Kuac.” Dostop 18. September 2017. http:// www.art-c.keio.ac.jp/.

Kokuritsu Nögakudo hachigatsu: Natsu Supesharu (5.8.2011) (Nacionalno gledališče nō: poletni program). 2011. Tokyo: National Nō Theater.

Nomura, Noriko, ur. 2007. Purodakushon nōto: Teshigahara Hiroshi, Eiga kotohajime『プロダクションノート: 勅使河原宏・映画事始』(Produkcijski zapiski: Hiroshi Teshigahara, filmski začetki). Tokyo: studio 240.

Omega Point: Experimental, Avant-garde, Noise, Sound-art. 2015. "Toshi Ichiyanagi + Kenji Kobayashi ‘Duo Recital'.” Dostop 20. September 2016. http:// omega-point.shop-pro.jp/?pid=102101182.

post (Notes on Modern \& Contemporary Art around the Globe). 2013. "Sōgetsu Art Center (arhival materials).” Dostop 13. september 2016. http://post. at.moma.org/themes/4-Sōgetsu-art-center.

Rajikaru Concert: An Evening of Works by Ichiyanagi, Kosugi, Ono, and Shiomi. 2007. Program Notes to the Concert Complementing the Exhibition Art, Anti-Art, Non-Art: Experimentations in the Public Sphere in Postwar Japan, 1950-1970, Harold M. Williams Auditorium, The Getty Center, April 27. https://www.getty.edu/research/exhibitions_events/events/rajikaru_concert_program.pdf.

Saigen Sögetsu Äto Sentā 再現草月アート・センター (Obuditev umetniškega centra Sōgetsu). 1987. Tokyo: Zaidanhōjin Sōgetsukai.

Sakkyokuka shüdan reikai sukejūru 作曲家集団例会スケジュール (Spored Skladateljskega sestava, brošura). 1960. Tokyo: Hiroshi Teshigahara.

Siddons, James. 2001. Töru Takemitsu: A Bio-bibliography. Westport: Greenwood Press.

Sögetsu Āto Sentā 草月アート・センター (Umetniški center Sögetsu). 1958. Tokyo: Hiroshi Teshigahara. 
Sögetsu Atto Sentā: Insatsubutsu toiu 'banei' 草月アートセンター: 印刷物とい

う「半影」(Into the Penumbra of Printed Matter: Soggetsu Art Center, 19581971). 2009. Tokyo: MARM in Keio University Art Center.

Sōgetsu Ikebana 草月生け花. “Sōgetsu o shiru: Nenpyō de miru Sōgetsu no Rekishi 草月を知る: 年表で見る草月の歴史 (O Sōgetsu: Zgodovinska časovnica delovanja Sōgetsu).” Sōgetsu Ikebana. Dostop 19. maj, 2011. http:// www.sogetsu.or.jp/know/about/timeline/. 